Elisa Paganini

Università degli Studi di Milano

\title{
Vague Fictional Objects
}

[Final draft 2019 - forthcoming in Inquiry]

\begin{abstract}
I propose a different account of fictional objects from the ones already present in the literature. According to my account, fictional objects are culturally created abstract objects dependent for their existence on the pretence attitude adopted by a group of people towards a single fictional content. My work is divided into three parts: in the first one, I present how fictional objects come into existence according to my proposal; in the second part, I illustrate how the existence of fictional objects so conceived may be ontically indeterminate; in the last part, I consider what happens when vague existence and indeterminate identity are claimed within fictional texts.
\end{abstract}

Keywords: fictional objects; vagueness; ontic vagueness; creationism about fictional objects. 


\section{Introduction}

The debate on fictional objects divides participants into realists and irrealists. According to realists, a fictional object is the referent of a name or description originating in a work of fiction and used either inside or outside it. ${ }^{1}$ According to irrealists instead, we can do without fictional objects as the author(s) and the receivers of a fictional work use names and descriptions originating in a work of fiction, pretending to refer but not referring. ${ }^{2}$ The idea shared by both parties is that works of fiction bring with them rules for interpreting and using names and descriptions originating in them. They are divided by the account of these rules.

My claim is that a work of fiction is not to be considered as already equipped with rules for using it, but - at least in paradigmatic cases - as a proposal presented by the author (or authors) to the receivers of the fiction. The idea is that the author of a work of fiction intends to offer the recipients a certain content in order to engage in pretence, and the offer may be successful or not. In less paradigmatic cases, a certain group of people may agree to engage in pretence over a content even if the author did not have a pretence attitude towards it, in this case what is relevant for the existence of fictional objects is that a group of people share a content and a pretence attitude towards it. ${ }^{3}$ According to this approach, the existence of a fictional object

\footnotetext{
${ }^{1}$ Among realist philosophers, meinongians include: Rapaport 1978, Parsons 1980, Routley 1980, Zalta 1983, Berto 2011; and creationists include: van Inwagen 1977, Searle 1975, Schiffer 1996, Salmon 1998, Thomasson 1999, 2003, Voltolini 2006, Bonomi 2008, Kripke 2011, 2013. According to some realists, fictional names or descriptions refer outside fiction but not inside it [see for example Kripke (2013, p. 81)], while according to others they refer both inside and outside fiction [see for example Parsons (1980, p. 52)].

${ }^{2}$ Among the irrealists are: Evans 1982, Walton 1990, Brock 2002, Sainsbury 2010, Everett 2013. For an overview of the debate on fictional characters on the irrealist side, see Friend 2007.

${ }^{3}$ In some cases, a fictional text is introduced by an author who believes that the content is not fictional (this is the case of myths which were introduced with the intention of reporting facts that had really happened, but are then
} 
depends on the pretence attitude shared by a group of people towards a single content: if pretence is shared towards a common content, there is a common usage of names and descriptions originating in fiction and this allows for the existence of fictional objects, otherwise fictional objects do not come into existence. My suggestion is therefore that fictional objects are culturally created objects dependent for their existence on the common pretence attitude adopted by a community of people towards a shared fictional content.

My proposal is, then, on the realist side. I claim that fictional objects exist as created abstract objects. But my account of them is quite different from those of other realists, according to whom the existence of fictional objects relies on the fictional text or on the fictional text together with the pretending intentions of the author (or the authors) $;{ }^{4}$ in my opinion, a crucial role is played by the receivers of fiction and the pretence attitude adopted by a group of people towards a shared content.

My approach is not irrealist. I maintain that the existence of fictional objects depends on a certain successful use of pretence, while irrealists claim that pretence does not imply a commitment to fictional objects. ${ }^{5}$

If my approach is adopted, not only may a different account of fictional objects be given, but their ontic vagueness may also be coherently vindicated. Let me say how I am going to proceed. First of all, I present how fictional objects come into existence according to my proposal, explaining the difference between my proposal and the existing ones $(\S 1)$. Then, I

considered as fiction - see Caplan 2004, p. 334 and Braun 2005, p. 614) or it is not introduced by the intentional act of a human being (this is the imaginary case of a fictional text introduced by chance, for example, by the casual typing of a monkey). In such cases, it is essential that a common content is shared by at least some receivers who engage in a pretence attitude with it.

${ }^{4}$ See for example Searle (1975, p. 330), Thomasson (1999, p. 6).

${ }^{5}$ See for example Walton (1990, p. 396); Brock (2002, p. 9); Everett (2013, p. 1). 
will argue that if my characterization of fictional objects is adopted, there is a coherent way to argue for their ontic vague existence $(\S 2)$. In the last part of my work, where I consider what happens when vague existence and indeterminate identity are asserted within fiction, I will claim that a fictional text may allow for vague existence and indeterminate identity of fictional objects in principle, but we have reasons for excluding that it allows for them in the actual world (at least in the present situation) (§3).

\section{On the existence of fictional objects}

If we try to voice the pre-theoretical idea concerning the origin of fictional characters and fictional stories, we may want to appeal to what goes on in the mind of the author of fiction. The author of fiction may just use stereotyped figures in order to create her fictional stories, as may happen when we want to tell a new tale to a child in an unplanned situation; but the author of fiction may go through a more sophisticated elaboration of fictional characters trying to develop a story heard or a certain event imagined in order to come up with a fictional story, as is described - at least according to certain interpretations - in Pirandello's "Six characters in search for an author", where six underdeveloped characters obsessively occupy an author's mind with the aim of being expanded and fleshed out in more detail, so as to be part of an adequately accomplished fictional story. The pre-theoretic explanation of the origin of fictional characters therefore makes explicit reference to what goes on in the mind of a fictional author and it is when this mental process comes to an end that the author shares her mental creation with the receivers through a medium (be it prose, poetry or play).

This pre-theoretic importance given to the mental activity of the fictional author neglects the objectivity of the fictional content transmitted by the author to the receivers. It is this objective content transmitted through fictional texts which is the main concern of philosophers. This is why they have ignored what happens inside the mind of any fictional author in preparing her 
work because this is subjective and not objective, and whatever is subjectively held in the mind of a single person cannot account for the objective existence of fictional objects (if there is any). The main philosophical concern is instead the objective fictional content transmitted from the author to the receivers of fiction.

It is important to note that, though the mental activity of the fictional author is not considered to be philosophically relevant in order to establish whether there are fictional objects or not, the activity of the fictional author is important: the pretence attitude with which the fictional text is produced by the author and entertained by the receivers is actually considered crucial. ${ }^{6}$ It is generally taken for granted that it is this attitude which accounts for the interpretation fictional texts deserve.

Once a text is considered to be fictional because of the intentional attitude adopted by author and/or receivers towards it, the objective content transmitted by the text is usually considered to be defined by rules which are established independently of the actual users of fiction and which may or may not actually be acknowledged by them. The way in which these rules are characterized is what distinguishes the different theories of fiction.

A distinction is generally made between philosophers who maintain that we may give a literal extensional interpretation to fictional language, ${ }^{7}$ those who claim that we should consider any fictional assertion within the scope of an intensional fictional operator (i.e. for any fictional assertion "P" in a fiction F, we should interpret it as "Within fiction F, P") ${ }^{8}$ and those who think that the objective content transmitted within fiction can be accounted for only in terms of rules which govern games of make-believe or practices of interpretation. ${ }^{9}$ Once it has been

\footnotetext{
${ }^{6}$ See for example Searle (1975, p. 320), Walton (1990, p. 39), Lamarque (2000, p. 98), Kripke (2013, p. 29).

${ }^{7}$ See for example Rapaport 1978, Parsons 1980 and Routley 1980.

${ }^{8}$ See for example Lewis 1978, Currie 1988 and 1990 and, Thomasson 1999.

${ }^{9}$ See for example Walton 1990, Lamarque and Olsen 1994, Crimmins 1998, Everett 2013.
} 
established which rules account for the objective content of fictional discourse, the question of whether there are fictional objects is taken into account and it is generally acknowledged that whoever adopts a literal interpretation of fictional discourse is committed to fictional objects, ${ }^{10}$ while whoever claims that fictional discourse has either an intensional or a pretence-theoretic interpretation is not committed to them.

Even if the rules they propose in order to account for the fictional discourse are very different and incompatible, ${ }^{11}$ all theories of fiction are committed to the existence of rules intended to establish what is objectively conveyed through fiction quite independently of what is acknowledged by the users. My proposal is to call into question the assumption that there are rules - quite independent of the actual users - which allow us to establish the objective content transmitted through fiction. I do not have conclusive arguments to show that this assumption has to be abandoned, but I propose two considerations which - in my opinion - are reasons to take into account the alternative I am going to offer.

The first consideration has to do with the fact that whatever rules are adopted in order to account for the objective content of a fictional story, we may find cases such that there is no rule settled for them or any rules adopted are recognized to be arbitrary. ${ }^{12}$ The types of fictional text which allow for the unsettledness of rules or for arbitrary rules change from theory to theory

\footnotetext{
${ }^{10}$ It is generally assumed but not accepted by everyone. For example, Azzouni (2010) argues that a sentence may be true or false even if what is being spoken of does not exist.

${ }^{11}$ But there are also philosophers who want to make the different approaches compatible; see for example Zalta 2000 who proposes to show that pretence-theoretic notions can be systematized within the framework of a theory allowing for the existence of fictional objects or Voltolini (2006) who adopts a syncretistic account of fictional objects.

${ }^{12}$ The philosophers who explicitly consider the absence or the arbitrariness of rules for establishing in certain cases how many fictional objects a particular fiction allow to exist are Caplan and Muller (see Caplan and Muller 2014 and 2015).
} 
and it is not my concern here to go through them. ${ }^{13}$ What I am interested in instead, is to consider the following question: if we allow for cases in which rules are settled and not arbitrary, and cases in which rules are either unsettled or arbitrary, what is it that establishes the settledness or arbitrariness of rules? The answer some may want to give is that when people uniformly adopt a single interpretation when confronted with a specific fictional text, the rule is settled; when people confronted with a certain fictional text suspend judgement or adopt incompatible interpretations, rules are unsettled or arbitrary. It may therefore be observed that while rules were introduced in order to account for the objective content of a fictional text independently of the actual users, the users are considered relevant in order to establish whether the rules are established or not.

My second consideration is dependent on the first one. If we admit the importance of the actual reaction of people towards fictional texts in order to establish whether something objective is transmitted by these texts or discourses, we may at least wonder whether the objectivity we are looking for is to be sought in the attitudes of the people involved. Is there any way to account for the objective content transmitted by a fictional text which appeals to people's reactions? I believe that we may account for the objective content of such texts or discourse appealing to the common display of certain dispositions by a group of people (this is what I am going to consider in $\S 1.1$ below).

Once a single content is shared by a group of people, they may choose whether to engage in pretence with it or not. This choice is important for the critical attitude people may adopt

\footnotetext{
${ }^{13}$ In order to consider cases of indeterminate identity between fictional characters because there is no fact of the matter, see Parsons $(2011$, p. 37). In order consider cases for indeterminacy in the correct intensional interperpretation of fictional discourse, see Lewis 1978, (reprinted in 1983, pp. 271-272) where it is discussed whether little-known or unknown facts are relevant for fictional truth or not. In order to consider arbitrariness of games of make-belief see Walton (1990, p. 397).
} 
towards fiction: they may decide that the fiction has been well developed, badly developed, underdeveloped, is inadequate or whatever other judgement they may decide to adopt. Pretence (and this is what I am going to argue in $\S 1.2$ ) depends on such a judgement and, if at least some of the receivers agree to engage in pretence towards a single content transmitted to them, then fictional objects arise according to my proposal. My goal in $\S 1.2$ is to give an account of fictional objects in terms of pretence.

\subsection{Content}

According to my proposal, the objective content conveyed by a fictional text is not to be looked for in rules which apply to it independently of the actual users, but in the actual dispositions of the receivers of fiction. In particular, according to my proposal, the content of a work of fiction is established by the possible situations (i.e. fragments of possible worlds) both the author and the receivers of a work of fiction would acknowledge as adequately described by the fiction itself, were they required to do so. The actual understanding of the author and the receivers of the fiction is therefore essential in order to establish the fictional content.

My definition of what it is for a fictional text to express a single content is the following:

(SFC) A fictional text allows for there being a single fictional content transmitted from the author(s) to the receivers if and only if there is at least one possible situation such that the author(s) and/or the receivers would acknowledge as adequately described by the fiction itself and there is no situation such that some of the author and receivers would consider it as definitely described by the fiction while others would consider as definitely not so described. 
It may be important to note that a single fictional content is not to be interpreted as a single possible situation individuated by a group of people as adequately described by the fictional story, but as a range of possible situations, some of them non-controversially compatible (or incompatible) with it and some of them such that it is controversial whether they are compatible with it or not. Singularity of the content does not correspond therefore to singularity of a possible situation acknowledged as described by the story. What is relevant is that to the singularity of the content corresponds a singular set of possible situations recognized as adequately described by the fictional story. ${ }^{14}$

Let us consider an example. Suppose that in a fiction we read "Mary is tall"; both the author and the receivers may agree that a situation in which a person called Mary is two meters tall is adequately described by the fictional sentence; a situation in which a person called Mary is one meter $68 \mathrm{~cm}$ tall may allow for different inclinations among author and receivers, but there would not be one person who thinks that it is definitely described by the text and another who says that it is definitely not so described. This shows that the content of a fiction may have levels of indeterminacy as the existence of a fictional content does not require a complete agreement among the receivers, it is sufficient that there is a partial agreement (a situation allowed by everyone as adequately described by the fiction) and a partial disagreement (a situation which allow for a moderate difference among the reaction of the receivers).

It is compatible with the above definition of fictional content that there may be cases in which no fictional content is transmitted from the author to the receivers. Consider for example a metaphorical sentence like "Juliet is the sun"; it may be that there is no situation such that both author and receivers agree that it satisfies the fictional content of the sentence and therefore

\footnotetext{
${ }^{14} \mathrm{~A}$ consequence of the theory is that fictions describing impossible situations do not express a single fictional content: there is no possible situation any group of people would acknowledge as adequately described by the fiction.
} 
it may be the case that the sentence does not have a single fictional content. This does not prevent receivers appreciating the fictional sentence above, I am just saying that this sentence presumably does not express a single fictional content.

A single sentence in a fictional work not expressing a single content does not prevent the fiction from having a fictional content, it is just that any fictional sentence not expressing a single content does not contribute to the constitution of the fiction's single fictional content. It is sufficient for at least some sentences in the fiction to have a single fictional content for the fiction itself to have a single fictional content.

The main difference between my proposal and the other theories is not that I claim that not all fictional sentences express a single fictional content while the other theories claim that any sentence has a precise content, because many theories of fiction would agree that a metaphorical sentence does not have a precise content or interpretation. The difference is in the explanation of the absence or arbitrariness of any content or interpretation. For a philosopher who claims that rules of language and interpretation exist independently of the actual users, the absence or arbitrariness of such rules in certain cases is a primitive fact. According to my proposal, the presence or absence of a single content for fictional sentences actually depends on shared dispositions of the users of fiction and, the absence or arbitrariness of a single content is explained in terms of the absence of such dispositions or of a conflict among them. My proposal is therefore to consider the objectivity of fictional content as dependent on what is actually shared by a group of people confronting a fictional text.

\subsection{Pretence and fictional objects}

Even if not all fictional sentences originating in fiction have a single content, a fictional text with a single fictional content is a necessary prerequisite in order for fictional objects to be introduced. Let us consider why. A single fictional content transmitted from the author to the 
receivers - or shared among certain receivers - is a guarantee that something objective is communicated. Even if the single fictional content is defined in terms of the dispositions of author and receivers, its objectivity is guaranteed by the set of possible situations (or fragments of possible worlds) towards which the dispositions of author and receivers are directed.

Once a unique fictional content (as described above) is transmitted from the author to the receivers, the receivers may decide whether to engage in pretence with it. In order to be engaged in pretence, the fictional content should satisfy subtle needs of the receivers that are difficult to specify but may include the aesthetic, moral and - perhaps even - religious expectations of the subjects involved.

It may be useful to say that I am not implying that the engagement in pretence presupposes a kind of pleasure or gratification, since a person may engage in pretence towards a content she would define as disgusting or boring. What I am trying to say is that the reasons for the involvement in pretence are hard to identify, but that this engagement in pretence by a group of people towards a fictional content is what allows a text to become a cultural object. And culture is not something that exists because of rules or dispositions, as it requires more subtle choices. And my proposal is that fictional objects are culturally created abstract objects which depend on this subtle choice.

A simple example may show that pretence cannot be taken for granted. Suppose that an aunt tells a newly created fairy tale to her four-year-old niece: the niece may enjoy the content of the new fairy tale and engage in pretence, or she may refuse it, saying something like: "he isn't a prince, a prince doesn't behave like that". If the storyteller's offer fails (for example, because the prince does not marry the princess by the end of the tale and the four-year-old girl is disappointed by it), then the receiver refuses the invitation. In this second case, the receiver has grasped the single fictional content very well, but refused to engage in pretence with it. This example not only shows that pretence depends on a subtle choice which has to do with 
expectations, but also that, according to my proposal, to engage in pretence is not equivalent to adopting certain rules of interpretation of the fictional text, it is, instead, after a fictional content has been attributed to the fictional text that the receivers may decide whether to engage in pretence with it or not.

It may be objected that pretence is not necessary for there to be fictional objects, because a single fictional content connected to names and descriptions in fiction is itself sufficient for them to exist. The objector may therefore ask: why do we need pretence in order for fictional objects to come into existence ${ }^{15}$

In order to answer this question, it may be useful to remember that with regard to fictional objects, a creationist philosopher needs an explanation for such objects to come into existence. Let us consider what allows abstract objects to be introduced by those who accept them; it is commonly acknowledged that the intentional actions of certain people are enough to introduce them: for example, laws are introduced by certain actions of authorized legislators, marriages are authorised by invested officiants, promises are made by people able to understand and keep them. ${ }^{16}$ In any such case, we see that the actions that allow for the existence of an abstract object are performed by people either publicly invested to introduce them or completely responsible for what they do. In the case of fiction, the author obviously has the intention to offer a text involving pretence, but this attitude of the author may not be successful as the receivers may refuse to be engaged in the pretence, even if they attribute a single content to it. The authority of the fictional author is retrospective (when she has it): it is when the receivers agree to engage in pretence with the fictional story, that the action of the author becomes creative, otherwise it fails to be so. And it is this engagement in pretence by author and receivers that allows for the existence of fictional objects, as they are objects that respond to subtle needs of the people involved and for this reason they become cultural objects.

\footnotetext{
${ }^{15} \mathrm{I}$ am indebted to an anonymous referee for pressing me on this point.

${ }^{16}$ See for example Thomasson (1999, pp. 12-13).
} 
Now, a fictional object exists whenever a group of people agree to engage in pretence towards a single content obtained through fictional sentences including either a name or a description of an object. Whenever a text expressing a single fictional content contains names or descriptions of an object, a single fictional content is connected with such names or descriptions. And whenever a community agrees to engage in pretence with such a content, the objective, shared content is accepted both emotionally and critically and this allows for the objective cultural existence of the object described.

Let us consider, by way of an example, Kafka's Metamorphosis. According to the fiction, the salesman Gregor Samsa wakes up one morning inexplicably transformed into a huge, filthy insect. Now, what makes Gregor Samsa a fictional character is not just that the receivers of the novel share a single fictional content connected to the name 'Gregor Samsa'; what allows him to be a fictional character is that most (or, at least, some) receivers are involved in pretence with the content. It is this latter involvement which allows for the existence of the fictional character Gregor Samsa.

It may be useful to compare my proposal on fictional objects to other existing ones. According to other creationists, fictional objects are created abstract objects dependent for their existence on the intention of the author when introducing the fictional text and on the use of it by the receivers. ${ }^{17}$ It is not acknowledged that the involvement in pretence as the satisfaction of subtle needs plays any role in fictional objects coming into existence, as I am instead claiming in the present work. I suspect that the origin of the difference is a different attitude towards fictional language. While it is generally taken for granted that language is fictional because of the attitude of the people using it, it is supposed that the linguistic expressions introduced with a fictional attitude have semantic rules independent of the actual users. I propose instead that fictional language is to be constantly interpreted together with the

\footnotetext{
${ }^{17}$ See Schiffer (1996, p. 156), Thomasson (1999, p. 35), Kripke (2013, p. 76).
} 
dispositions and attitudes of the users: it has a content if the users are disposed to give it a single fictional content and it allows for the existence of fictional objects if the users are engaged in pretence with the fictional story.

It may be observed that not every name or description originating in fiction allows for the existence of fictional objects according to my proposal, and thus that my claim is more parsimonious than other realist theories of fictional objects. ${ }^{18}$ This is correct, but I do not think that a realist theory should be evaluated on the basis of the number of objects allowed, it should instead be evaluated for the account given of them. According to the present suggestion, for fictional objects to be cultural objects, two factors are necessary: (i) a shared disposition of a group of people to attribute a common content to a fictional text and (ii) a shared pretence attitude towards that content. The idea proposed is that cultural objects do not simply depend on fictional texts and rules for them, but on how people actually behave. It is this approach which should be taken into consideration in order to evaluate the theory.

Before concluding this section, let me add as an aside something about reference of names and descriptions originating in fiction. Whenever a fictional text does not express a singular fictional content, names and descriptions originating in it do not refer. Whenever a fictional text expresses a singular fictional content, two options are equally available: if the receivers refuse to pretend, then names and descriptions originating in fiction do not refer; if on the contrary at least some receivers agree to adopt a pretence attitude towards a single fictional content conveyed, they pretend to refer when they use names and descriptions within fiction but they refer to the pretended object when they use the same names and descriptions outside fiction. The name 'Gregor Samsa' does not refer within fiction, it refers outside fiction to the socially pretended shared fictional content connected with the name 'Gregor Samsa' ${ }^{19}$

\footnotetext{
${ }^{18} \mathrm{I}$ am indebted to an anonymous referee for this observation.

${ }^{19}$ My proposal concerning reference of names originating in fiction is in line with Kripke's in Kripke 2013, p. 81.
} 


\section{Fictional objects and vagueness}

I have claimed that the existence of fictional objects is strictly connected to the pretence attitude adopted by both the author and at least some receivers towards a single fictional content originated by a fictional text containing names or descriptions. My definition of what it is for a fictional object to exist is the following:

(FO) $i$ is a fictional object iff a group of people adopts a pretence attitude towards a single fictional content obtained from a fictional text with names or descriptions of $i$

Now, the people acknowledging a single fictional content may have different reactions to it: they may engage in pretence, they may refuse to engage in pretence, but they may also adopt intermediate attitudes.

As an example of the latter attitude, suppose for example that you are reading a novel where a very cowardly character is described: you are engaged in pretence with her, but at a certain point you read that this cowardly character experiences regret for her behaviour; this latter portrayal contrasts with your deep assumptions concerning cowardice, you may believe that regret requires a form of courage incompatible with cowardice and you do not want to pretend that the character regrets her behaviour. Your pretence attitude is then indeterminate, I claim, and you indeterminately pretend to refer to the character outside fiction. If no receivers agree to engage in pretence with a shared fictional content and some of them adopt only a partial pretence attitude, it is indeterminate whether the relevant fictional objects exist.

To put it in a nutshell, according to my proposal, existence of fictional objects comes with the pretence attitude adopted by a group of people towards a single fictional content conveyed; 
as long as the pretence attitude may be indeterminately adopted, existence of the fictional objects may itself be indeterminately instantiated. But, let us distinguish between a case of indeterminate existence (as the one described above) and a case of partially indeterminate existence. The latter is the case in which at least some receivers agree to engage in pretence with a certain content connected with a fictional object, while others adopt an indeterminate pretence attitude towards the same content: in this case the existence of the fictional object becomes only partially indeterminate.

\subsection{Everett's argument against vague fictional objects}

In order to test my proposal, I will consider a famous argument proposed against fictional objects because of their vagueness by Everett (2005 and 2013) and look at the reply to it by anyone endorsing my claim. The argument may be summed up by two premises and a conclusion in the following way:

1. If there are fictional objects, then it can be ontologically indeterminate whether a fictional object exists

2. It cannot be ontologically indeterminate whether a fictional object exists

C. Therefore, there are no fictional objects

This argument has been already considered by realist philosophers and it has generally been argued that the first premise is false, either because fictional objects cannot exist indeterminately or because their indeterminacy or vagueness is semantic only and not ontic. ${ }^{20}$

\footnotetext{
${ }^{20}$ Among philosophers who argued that fictional objects cannot indeterminately exist see Voltolini 2010 (according to whom a fictional object may have the external (to the fiction) property of existing and the internal (to the fiction) property of indeterminately existing) and Schnieder and von Solodkof 2009 (according to whom
} 
What I want to claim is that the first premise is correct (even though my reasons for accepting it are different to those attributed to a realist by Everett), while, instead, the second premise is to be dismissed. I will consider the two premises separately, I will take into account how Everett maintains that a realist is committed to each of them and I will present my reaction to each of them.

\subsubsection{The first premise}

The first premise of the argument says:

1. If there are fictional objects, then it can be ontologically indeterminate whether a fictional object exists

Now, according to Everett, any realist philosopher is committed to the following necessary and sufficient conditions for the existence of a fictional object:

(E) $i$ is a fictional object iff (a) some fiction is such that, in that fiction $i$ exists and (b) $i$ is not a real thing (Everett 2013, p. 226)

It is quite evident that if (E) is accepted, it follows that whenever conditions (a) and (b) are indeterminately instantiated, it is indeterminate whether a fictional object exists. But condition (E) cannot be accepted by anyone who is ready to allow that the existence of a fictional object

the determinate existence of fictional objects is not called into question by claims of indeterminacy in the fictional text), criticized by Caplan and Muller 2014 and 2015. Among philosophers who have claimed that fictional objects' vagueness is semantic only see Thomasson 2010, Cameron 2013, Murday 2015 and Woodward 2017. 
does not depend on names and descriptions in the fictional text not referring to real things, but instead depends on the pretence attitude.

According to (E), Napoleon in Tolstoy's War and Peace is not a fictional character. And this observation is partially correct as the name "Napoleon" has a reference in our world and it does not lose this reference when it is used in the fictional text: we may say that the real Napoleon is part of the fictional story. But there is also a reason why the name "Napoleon", used within fiction allows for the existence of a fictional character. The reason is that when we use the name within fiction, we consider properties he has in fiction and it cannot be taken for granted that he also has them in real life. He is therefore part of a single fictional content which we may want to pretend, but not believe. It is when we pretend a single fictional content connected to the name "Napoleon" that Napoleon becomes a fictional character. We may therefore abandon condition (b) in (E) for the existence of fictional objects.

Moreover, according to (E), any fictional use of a name without reference in the real world should be a necessary and sufficient condition for the existence of a fictional character; but, in my opinion, if a character is not accepted within pretence by the receivers, it does not exist. As I have tried to argue, it is not sufficient to write in fiction "Mr Nobody does so-and-so" in order for there to be the fictional character Mr Nobody. According to my proposal, the existence of fictional objects is not dependent simply on what is written in the fictional text, it depends on the pretence attitude adopted by a group of people towards a single fictional content.

I offered condition (FO) for the existence of fictional objects. Let me just repeat it here:

(FO) $i$ is a fictional object iff a group of people adopts a pretence attitude towards a single fictional content obtained from a fictional text with names or descriptions of $i$ 
This condition allows for the first premise to be true but for a different reason from the one proposed by Everett: while I allow there being vague existence of fictional objects whenever it is indeterminate that some people adopt a pretence attitude towards a relevant single fictional content, Everett claims instead that - according to realists - their vagueness depends on the indeterminacy in the fictional description of objects that are not real. As I maintain that a fictional text by itself cannot be responsible for the existence of fictional objects, I refuse Everett's characterization of fictional objects (i.e. (E)) but I accept the first premise of his argument because it follows from (FO) and the recognition that the pretence attitude may be indeterminately instantiated.

\subsubsection{The second premise}

Let us now consider the second premise of Everett's argument, which says:

2. It cannot be ontologically indeterminate whether a fictional object exists

In order to support this premise, Everett considers three possible ways to characterize ontic indeterminate existence for fictional objects, he claims that all three of them are inadequate and he concludes that there cannot be ontologically indeterminate existence for fictional objects.

Let me present the second option considered by Everett: he observes that in order for it to be indeterminate whether a fictional object exists, we may want to maintain that it is indeterminate whether the property of "being a fictional object" is instantiated, but this proposal is inadequate in his opinion because it presupposes the existence of an object indeterminately instantiating the property "being a fictional object". His words are as follows: 
"in order for it to be indeterminate as to whether a property is instantiated, there must surely be an object or set of objects such that it is indeterminate as to whether they instantiate that property. [...] Now if the property of being the $[\mathrm{P}]$-character is indeterminately instantiated then it must be indeterminately instantiated by a fictional character.” (Everett 2005, p. 632)

He is claiming that the inference from $\nabla \exists \mathrm{xPx}$ (to be read: it is indeterminate whether there is an object which instantiates the property $\mathrm{P}$ ) to $\exists \mathrm{x} \nabla \mathrm{Px}$ (to be read: there is an object such that it is indeterminate whether it instantiates the property P) should be taken for granted.

As is well known, this inference - let us call it the inference from indeterminacy - has a crucial role in any debate on vague existence. The debate on vague existence has long concerned physical composite objects, but more recently it has been directed towards abstract objects. The debate may be better understood if it is acknowledged that the detractors of ontic vagueness maintain that any vagueness is semantic, while the supporters of ontic vagueness claim that vagueness may depend on the way the world is in itself, quite independently of any rule of language. When the detractors of ontic vagueness consider the inference from indeterminacy, they presuppose that the indeterminacy in the premise (i.e. $\nabla \exists x P x$ ) is to be attributed to the vagueness of a linguistic device: either of the existential quantifier or of the first-order predicate; they exclude that the (unrestricted) existential quantifier may be semantically vague and this is the reason why, in their opinion, the quantifier cannot be responsible for the indeterminacy; it follows that only the first-order predicate can be responsible for vagueness and therefore the inference to the conclusion (i.e. $\exists \mathrm{x} \nabla \mathrm{Px}$ ) is allowed. $^{21}$

\footnotetext{
${ }^{21}$ This strategy was adopted by Lewis 1986 and Sider 2001. I will reconsider their proposal in §3.2.
} 
The supporters of ontic vagueness (see for example van Inwagen 1990 and Korman 2015) claim instead that indeterminate existence depends on how the world is, quite independently of the rules governing any linguistic device. In the case of composite objects, the idea is that their existence is the result of complex relations among already existing parts: as long as these relations may be indeterminately instantiated, it may be indeterminate whether a composite object exists, without there being a determinately existing object indeterminately instantiating the property of being composed by those parts. ${ }^{22}$

An analogous argument may be adopted by any supporter of vague abstract objects and in particular by a supporter of vague fictional objects who accepts my proposal. According to my definition of fictional objects (FO), the existence of a fictional object is dependent on the complex attitude of pretence adopted by a group of people towards a single fictional content. As long as the pretence attitude may be indeterminately adopted, it may be indeterminate whether a fictional object exists without there being any definitely existing object indeterminately instantiating the property of being a fictional object.

In order to understand this idea, let us consider that, in order for there to be fictional objects, it is presupposed that there are human beings and single fictional contents shared by them. If there were not human beings able to tell and to understand fictional stories, fictional objects would not exist. Nor would they exist if human beings were unable to share a single fictional content when confronted with a relevant fictional text. Human beings and single fictional contents are therefore necessary conditions for the existence of fictional objects, but they are not sufficient - a shared pretence attitude towards a single fictional content concerning one or more objects is required. And whenever this pretence attitude is indeterminately instantiated, it is indeterminate whether a fictional object exists. It is therefore of crucial importance for my

\footnotetext{
${ }^{22}$ This approach to ontic vague existence was first proposed by van Inwagen 1990 and a more recent application to abstract objects is to be found in Korman 2015.
} 
approach to distinguish between the object towards which the pretence attitude is directed (i.e. a single fictional content) and the outcome of the shared pretence attitude (i.e. fictional objects). According to the present proposal, therefore, the existence of fictional objects depends on the pretence attitude that may hold between definitely existing objects, i.e. human beings and a single fictional content. As long as this pretence attitude may be indeterminately instantiated, it may be indeterminate whether a fictional object exists.

Let me sum up what I have argued for in this section. I claimed that it can be indeterminate whether a fictional object exists. I gave reasons why my definition of fictional objects is compatible with their indeterminate existence and presented how a supporter of my proposal may reply to Everett's argument, allowing for both the existence and the indeterminate existence of fictional objects.

\section{Vagueness within fictional texts?}

Even if my characterization of fictional objects and their indeterminate existence were accepted, it may reasonably be asked what happens when indeterminate existence or vague identity are explicitly claimed in the fictional text. ${ }^{23}$ It may be observed that, whenever vague existence and indeterminate identity are stated within the fictional text, allowing for a single fictional content to be definitely pretended by both the author and some receivers, vague existence and indeterminate identity of fictional objects may depend on the fictional text and not on the indeterminate pretence attitude adopted by a group of people.

My reaction to this remark is that it is correct in principle, but we have reason to believe that any actual fictional text where vague existence or indeterminate identity are offered to the receivers does not allow for a single fictional content to be conveyed. According to my proposal, if a fictional text does not allow for a single content to be shared by a group of people,

\footnotetext{
${ }^{23}$ Daniel Korman first made this observation. I am grateful for his useful remark.
} 
there is no objective common content towards which pretence may be directed, preventing pretence, as a social attitude, from being instantiated. And whenever pretence as a social attitude cannot be instantiated by a group of people, there is no culturally created fictional object. It is the aim of this last part of the paper to argue that, with the way things are in our world, fictional texts stating vague existence or indeterminate identity do not allow for a single fictional content to be transmitted.

\subsection{Indeterminate identity within fiction?}

Suppose that a fictional text includes the following sentence:

John underwent a very serious surgical operation such that it was indeterminate whether the person who awakened after the operation was identical to John.

A fictional sentence like this allows for three different incompatible interpretations of indeterminacy: the epistemic interpretation, the semantic interpretation and the ontic interpretation. According to the epistemic interpretation, there is a fact of the matter concerning the identity of John, while the indeterminacy claimed in the text is dependent on epistemic limits that do not make it possible to recognize the matter of fact. ${ }^{24}$ According to a semantic interpretation, the indeterminacy does not depend on epistemic limits, but on limits in the semantic rules associated with at least the word "person": the extension of the word "person" has not been established in sufficient detail and the situation described is such that it allows for there being a semantic borderline case of identity between persons. ${ }^{25}$ According to an ontic

\footnotetext{
${ }^{24}$ This interpretation of epistemic vagueness has been defended for example by Sorensen 1988 and Williamson 1994, pp. 185-198.

${ }^{25}$ Consider for example the supervaluationist theory introduced by Fine 1975.
} 
interpretation, persons objectively exist in the world, quite independently of any semantic rule governing the word "person" or any epistemic limits people may have; moreover, the fictional situation described above is to be considered as a case of indeterminate identity because of the way the world is and quite independently of any semantic rule or epistemic limit. ${ }^{26}$

If we accept that the three main theories of vagueness reflect three different ways by which we may interpret indeterminacy and vagueness, the three different incompatible interpretations of the text above prevent there being a single fictional content to be conveyed by it, as there is no single possible situation which would be acknowledged by any receiver as adequately described by the text.

It may be objected that it is possible to force one of the above interpretations and exclude the others. And if we want to force an interpretation and exclude the others, the first two are to be dismissed, while the third seems to be relevant in order to claim ontic indeterminate identity of the fictional objects. Let us consider why.

Suppose for example that the following text forces an epistemic reading of indeterminate identity:

John underwent a serious surgical operation; there was a definite fact of the matter establishing whether John was identical to the person who awoke or not, but, hard as they searched, people were unable to establish what it was, considering it therefore indeterminate whether John was identical to the person who awoke or not.

The epistemic description of indeterminate identity seems to be compatible with a single fictional content: there are at least two possible situations with a precise fact of the matter concerning John's identity (one in which John is identical to the person who awoke from the

\footnotetext{
${ }^{26}$ See for example Merricks 2017 for a defense of ontic vagueness.
} 
operation, the other in which he is different from him) and in both of them, human beings are unable to establish what it is. This text does not allow ontic indeterminacy in John's identity: in all situations allowed, there is a precise fact of the matter concerning John's identity and it is simply the case that people are unable to discover it. Supposing that the text above forces an epistemic reading of indeterminate identity, it does not describe a situation in which John's identity is indeterminate and therefore it does not require the receivers to pretend that the fictional character John has any indeterminate identity. For this reason, supposing that the above fictional text allows for a single fictional content, it does not describe a case of ontic indeterminate identity for the fictional character John. ${ }^{27}$

Let us now suppose that we are able to force a semantic reading through the following text:

John underwent a serious surgical operation; the person who awoke after the operation was examined with the most sophisticated instruments in order to measure both his physical and psychic continuity with John before the operation. But after all the measures were completed, it was not possible to say either that John was identical to the person who awoke or that he was not, because the rules governing the word "person" have not been sufficiently specified to establish such a relation between them.

In such a case, let us suppose that a single fictional content is transmitted to the receivers of the fiction: there are physical and psychic relations between John and whoever wakes up after the operation, which are perfectly established and measured by the most sophisticated instruments; it is because the semantic rules of the word "person" are not sufficiently specified that the precise relations between John and whoever wakes up cannot be described either as a case of identity between persons or as a case of non-identity. According to such a text, we

\footnotetext{
${ }^{27}$ It may be remarked that there are epistemic interpretations of vagueness compatible with semantic vagueness (see for example Soames 2003). I am not considering them here.
} 
should not expect John to have any indeterminate identity with whoever wakes up, independently of the semantic rules governing the word "person". Once again, in such a case, we do not have a description of ontic indeterminate identity of the fictional character John, because any indeterminacy depends on semantic rules. ${ }^{28}$

Now, in order to argue for a case of ontic indeterminate identity, we should at least have a fictional text excluding epistemic and semantic vagueness and forcing an ontic interpretation of indeterminate identity. Let us consider the following text as trying to force an ontic reading of indeterminate identity: ${ }^{29}$

Life began on Earth well before persons appeared. And there could have been life even if persons had never appeared. When dinosaurs existed, they existed because certain organisms had intrinsic properties that distinguished them from any other organism and independently of any belief, thought or language human beings may have developed afterwards. When persons started to exist, they existed for analogous reasons: they were organisms with intrinsic properties that distinguished them from any other organism and quite independently of any belief, thought or language human beings have developed about themselves.

Now let us concentrate on changes organisms may undergo. These changes may not be abrupt but gradual, instead, and they allow for living beings in general and persons in particular to undergo indeterminate relations. This is what happened to John who underwent a serious surgical operation.

\footnotetext{
${ }^{28}$ It may be objected that we do not have a way to characterize semantic vagueness that excludes ontic vagueness (see Taylor and Burgess 2015) or at least that any characterization of semantic vagueness is either a description of epistemic vagueness or of ontic vagueness (see Merricks 2001 and 2017). According to such an objection, my proposal to isolate the semantic reading of indeterminate identity is doomed to failure. It is not my intention to defend the idea that it is possible to force a semantic interpretation of indeterminate identity; consider that I am trying to reply to an objection to my thesis that a claim of indeterminate identity does not have a single fictional content and I am trying to see what would happen if it were possible to isolate the different interpretations of it; I do not claim that it is possible to isolate such different interpretations.
}

${ }^{29}$ Cohen 2017 claims that there may be fictions describing cases of metaphysically indeterminate identity. 
Because of the changes the person John underwent during the operation, it is objectively indeterminate whether he is the same person as the one who woke up afterwards or not.

Even if this text excludes both an epistemic and a semantic interpretation of indeterminate identity, this is not sufficient to introduce a single fictional content concerning ontic indeterminate identity. The problem is that we have reason to suppose that at least some (maybe most) readers would not be able to grasp a single possible situation that could be adequately described by the above text. If we limit ourselves to philosophers, it is possible to find public declarations that ontic vagueness is unintelligible and, that vagueness may be only either epistemic or semantic. ${ }^{30}$ Moreover, ontic indeterminate identity has been criticized not only for being unintelligible or inadequate, but also for being incoherent by Evans (1978) and Salmon (1981). There are therefore a good many philosophers who would claim that indeterminate identity is incoherent and that they are not able to attribute any content to any text purporting ontic indeterminate identity.

Their claim has been critically countered by philosophers who allow indeterminate identity to be intelligible and coherent, ${ }^{31}$ but there continue to be philosophers who still maintain that indeterminate identity is impossible. ${ }^{32}$ Now, in such a situation, it seems possible to deduce that there is no single fictional content that philosophers may actually grasp when indeterminate

\footnotetext{
${ }^{30}$ Among famous detractors of ontic vagueness are Russell (1923, p. 85); Dummett (1975, p. 314) [Dummett changes his mind, see Dummett (1981, p. 440)]; Lewis (1986, p. 212).

${ }^{31}$ Among philosophers who have offered a defense of ontic indeterminate identity: Broome 1984, van Inwagen 1988, 2009, Johnsen 1989, Lowe 1994, 2005, Parsons and Woodruff 1995, Parsons 2000, Williams 2008, Barnes 2009, Barnes and Williams 2009, Abasnezhad and Hosseini 2014, Zardini 2014, Fine MS.

${ }^{32}$ Among philosophers who have argued against ontic indeterminate identity (besides Evans and Salmon): Cook 1986, Pelletier 1989, Garrett 1991, 2014, Williamson 2002, Akiba 2000, Pinillos 2003, Smith 2008, Curtis and Noonan 2014.
} 
identity is claimed within fiction: some would not even be able to figure out what a situation in which indeterminate identity occurs would be like; others may claim to understand it but their accounts of it may diverge, so as to make incompatible metaphysical assumptions. ${ }^{33}$ And if philosophers do not agree on a single fictional content conveyed by a fictional text claiming ontic indeterminate identity, we may not assume that things might change if non-philosophers, too, were included among the receivers of fiction: there is no possible situation all people would recognize as adequately described by the above description of ontic indeterminate identity; it follows that the alleged fictional description of ontic indeterminate identity does not allow for a single fictional content to be conveyed.

\subsection{Vague existence within fiction?}

Things are no better when vague existence is claimed within fiction. The reason is that once again vague existence is a subject of debate in philosophy. As is well known, it has been claimed by Lewis (1986) and Sider (2001) that (unrestricted) existence cannot be vague. ${ }^{34}$ Their claim has been countered by supporters of vague existence. ${ }^{35}$ When the philosophical texts are approached, it is quite evident that the notion of existence adopted by the detractors of vague existence is different from the notion of existence adopted by their supporters, as already mentioned (see §2.1.2). According to the detractors of vague existence, the only way for existence to be vague is that the semantic rules of expressions involved in numerical sentences

\footnotetext{
${ }^{33}$ For example, in order to account for indeterminate identity some accept that the contrapositive of Leibniz's law is not perfectly true, without being completely false (e.g. Parsons and Woodruff 1995, p. 181), others claim that discussing Leibniz's law is the last resort of the defender of ontic indeterminate identity (e.g. Lowe 1994, p. 113).

${ }^{34}$ See also Sider 2003 and 2009.

${ }^{35}$ Among supporters of vague existence: van Inwagen (1990, ch. 19), Hawley 2002, Koslicki 2003, Barnes 2013, Korman (2015, ch. 9).
} 
are vague (but - they claim - such expressions cannot be vague and therefore, according to the detractors of ontic vague existence, there cannot be ontic vague existence). According to its supporters instead, vague existence is not dependent on semantic rules governing numerical sentences, it depends instead on how the world is, quite independently of any semantic rule.

In such a situation, we cannot expect philosophers to attribute a single fictional content to any fictional claim of vague existence: some of them would say that any claim of indeterminate existence is not ontic, but semantic or epistemic, others would say that the claim is ontic. We may acknowledge that the situation does not change when such fictional claims are received also by non-philosophers: we do not have any reason to assume that there is a single interpretation both philosophers and non-philosophers would give to any fictional claim of vague existence. ${ }^{36}$

\subsection{Historically oriented fictional preclusion to vague existence and indeterminate identity}

My claim is therefore that we have reasons to believe that, with the way things are in our world, fictional texts claiming indeterminate identity or vague existence do not express a single fictional content and therefore author and receivers cannot share a pretence attitude towards a single fictional content expressed by claims of indeterminate identity or vague existence. This

\footnotetext{
${ }^{36}$ Some readers may have a generally skeptical attitude towards my proposal, which considers the possible reactions of philosophers as a way to establish whether fictional sentences express a single fictional content. As an anonymous referee observed, philosophers disagree about all kind of things - about properties, about how many objects there are, etc. Should we conclude that a sentence like "Cinderella has blue eyes" does not express a single fictional content because philosophers disagree about properties (for example)? I believe that philosophers (nominalists and realists about properties) would agree on the possible situations which are adequately described by the fictional sentence above; their disagreement is ontological. The case under consideration in the text is different, philosophers do not seem to agree on which situations would be adequately described by the fictional sentences claiming vague existence or indeterminate identity.
} 
claim is obviously historically oriented; it does not exclude that in the future single notions of vague existence and of indeterminate identity may become popular and shared, allowing people to adopt a shared pretence attitude towards indeterminate identity and vague existence. ${ }^{37}$ This possibility does not contradict my proposal according to which fictional objects are culturally created abstract objects; they depend on the ability of people to share a single fictional content with certain sentences, and this ability may change over time.

My claim is simply that, in our present historical and cultural situation, we are unable to attribute a single fictional content to any fictional claim of vague existence or indeterminate identity. This inability prevents us from sharing a pretence attitude towards a single fictional content expressed by a fictional sentence claiming vague existence or indeterminate identity. According to my proposal, this present situation does not prevent cases of ontic indeterminate existence of fictional objects from occurring: the reason is that vague existence of fictional objects does not depend on an alleged single fictional content of a claim of vague existence, it depends on the indeterminate instantiation of a pretence attitude towards a single fictional content.

\section{Concluding remarks}

Let me sum up what I have done in this work. I have proposed considering fictional objects to be culturally created abstract objects, dependent for their existence on the pretence attitude of the author and receivers of a relevant fiction towards a shared fictional content. This idea

\footnotetext{
${ }^{37}$ Fine 2017 and MS argues that a single borderline case of indeterminate identity or vague existence is either to be denied altogether or to be explained in terms of global indeterminacy. This observation seems to prevent any single fictional content being conveyed by a fictional text claiming a single borderline case of indeterminate identity or vague existence. Even if this observation were correct, in my opinion borderline cases would hardly disappear from the philosophical community.
} 
requires a new notion of fictional content and a new conception of how fictional objects come into being; I have tried to give an initial picture of them in the first part of the paper in order to account for the way fictional objects come into existence $(\S 1)$.

In the second part (§2), I have claimed that the existence of fictional objects - as I describe them - may be ontically vague. I have considered a famous argument against fictional objects because of their vague existence and explained how a supporter of my approach may react to it.

In the last part of my paper ( $\S 3)$, I have taken into account fictional claims of vague existence or indeterminate identity. I have explained why I believe that, with the way things are in our world, no such fictional claims may express a single fictional content and therefore they may not originate cases of vague existence or indeterminate identity of fictional objects. But this observation is historically and contingently oriented and, things might well become different in the future. ${ }^{38}$

\footnotetext{
${ }^{38}$ This work is dedicated to my nieces, Chiara and Ilaria, for the beauty and wonder they have brought to my life and for the fairy tales they asked me to invent when they were children. - I presented this work at different stages of its elaboration in Padua, Pistoia, Dubrovnik, Munich and Valencia. I am deeply indebted to those who attended my presentations and raised questions or objections; among them, I recall Mark Balaguer, Francesco Berto, Andrea Bottani, Manuel García-Carpintero, Sam Coleman, Paul Egré, Stacie Friend, Aldo Frigerio, Heimir Geirsson, David Liggins, Daniel Korman, Sara Worley. I am particularly grateful to Alfredo Tomasetta and Alberto Voltolini, who read a previous version of this work and discussed it with me in minute detail. Two anonymous referees for this journal have been very helpful: using a constructive attitude they have forced me to explain my position better and to differentiate my proposal from others in the literature.
} 


\section{References}

Abasnezhad, A. and Hosseini, D. (2014), Vagueness in the World: A Supervaluationist Approach, in K. Akiba and A. Abasnezhad (eds), Vague Objects and Vague Identity, Dordrecht: Springer, pp. 239-55

Akiba, K. (2000), Vagueness as a Modality. Philosophical Quarterly 50: 359-70

Azzouni, J. (2010), Talking About Nothing: Numbers, Hallucinations and Fictions. Oxford: Oxford UP

Barnes, E. (2009), Indeterminacy, Identity and Counterparts: Evans reconsidered. Synthese $168: 81-96$

Barnes, E. (2013), Metaphysically Indeterminate Existence. Philosophical Studies 166(3): 495510

Barnes, E. and Williams, J. R. G. (2009), Vague Parts and Vague Identity. Pacific Philosophical Quarterly 90: 176-87

Berto, F. (2011), Modal Meinongianism and fiction: the best of three worlds. Philosophical Studies 152: 313-334

Bonomi, A. (2008), Fictional Contexts, in P. Bouquet, L. Serafini and R. H. Thomason (eds.), Perspectives on Contexts, CSLI Publications: Stanford, pp. 215-49

Braun, D. (2005), Empty Names, Fictional Names, Mythical Names. Nô̂s 39.4, pp. 596-631

Brock (2002), Fictionalism about Fictional Characters. Nô̂s 36(1): 1-21

Broome, J. (1984), Indefiniteness in Identity. Analysis 44(1): 6-12

Cameron, R. P. (2013) How to be a Nominalist and a Fictional Realist, in C. M. Uidhir (ed.), Art and Abstract Objects, Oxford: Oxford University Press, pp. 179-196

Caplan, B. (2004), Creatures of Fiction, Myth, and Imagination. American Philosophical Quarterly 41.4, pp. 331-337

Caplan, B. and Muller, C. (2014), Against a Defense of Fictional Realism. The Philosophical 
Quarterly (64.255): 211-224

Caplan, B. and Muller, C. (2015), Brutal Identity, in S. Brock and A. Everett (eds), Fictional Objects, Oxford: Oxford University Press, pp. 174-207

Cohen, W. A. (2017), Fictional Realism and Metaphysically Indeterminate Identity. Analysis 77(3): 511-19

Cook, M. (1986), Indeterminacy of Identity. Analysis 46(4): 179-86

Crimmins, M. (1998), Hesperus and Phosphorus: Sense, pretense, and reference. Philosophical Review 107:1-48

Currie, G. (1988), Fictional Names. Australian Journal of Philosophy 66.4, pp. 471-488

Currie, G. (1990), The Nature of Fiction, Cambridge: Cambridge University Press

Curtis, B. L. and Noonan, H. W. (2014), Castles Built on Clouds: Vague Identity and Vague Objects, in K. Akiba and A. Abasnezhad (eds), Vague Objects and Vague Identity, Dordrecht: Springer, pp. 305-26

Dummett, M. (1975) Wang's Paradox. Synthese 30: 301-24

Dummett, M. (1981), The Interpretation of Frege's Philosophy, Harvard: Harvard University Press

Evans, G. (1978), Can there be Vague Objects? Analysis 38(13): 208

Evans, G. (1982), The Varieties of Reference, Oxford: Clarendon Press

Everett, A. (2005), Against Fictional Realism. The Journal of Philosophy 102(12): 624-49

Everett, A. (2013), The Nonexistent, Oxford: Oxford University Press

Fine, K. (1975), Vagueness, Truth and Logic. Synthese 30: 265-300.

Fine, K. (2017), The Possibility of Vagueness. Synthese 194: 3699-725

Fine, K. (MS), Indeterminate Identity, Personal Identity and Fission, in Kit Fine's personal page on academia.edu

Friend, S. (2007), Fictional Characters. Philosophy Compass 2.2: 141-56 
Garrett, B. (1991), Vague Identity and Vague Objects. Nô̂s 25(3): 341-51

Garrett, B. (2014), Some Comments on Evans's Proof, in K. Akiba and A. Abasnezhad (eds), Vague Objects and Vague Identity, Dordrecht: Springer, pp. 275-82

Hawley, K. (2002), Vagueness and Existence. Proceedings of the Aristotelian Society 102: $125-40$

Johnsen, B. (1989), Is Vague Identity Incoherent? Analysis 49(3): 103-12

Korman, D. (2015), Objets. Nothing Out of the Ordinary, Oxford: Oxford University Press

Koslicki, K. (2003), The Crooked Path from Vagueness to Four-Dimensionalism. Philosophical Studies 114: 107-34

Kripke, S. A. (2011), Vacuous Names and Fictional Entities, in S. A. Kripke, Philosophical Troubles. Collected Papers, vol. 1, Oxford: Oxford University Press, pp. 52-74

Kripke, S. A. (2013), Reference and Existence. The John Locke Lectures, Oxford: Oxford University Press

Lamarque, P. (2000), Objects of Interpretation. Metaphilosophy 31.1/2, pp. 96-124

Lamarque, P. and Olsen S. H. (1994), Truth, Fiction and Literature. A Philosophical Perspective, Oxford: Clarendon Press

Lewis, D. (1978), Truth in Fiction. American Philosophical Quarterly 15(1): 37-46, reprinted in D. Lewis, Philosophical Papers vol. 1 (1983), New York, Oxford, Oxford University Press, pp. 261-75

Lewis, D. (1986) On the Plurality of Worlds, Oxford: Blackwell

Lowe, J. E. (1994), Vague Identity and Quantum Indeterminacy. Analysis 54(2): 110-14

Lowe, J. E. (2005), Identity, Vagueness and Modality, in J. L. Bermúdez (ed), Thought, Reference and Experience: Themes from the Philosophy of Garreth Evans, Oxford: Clarendon, pp. 290-310 
Merricks, T. (2001), Varieties of Vagueness. Philosophy and Phenomenological Research 62: $145-57$.

Merricks, T. (2017), Locating Vagueness. The Journal of Philosophy 114: 221-50.

Murday, B. (2015) Fictional Realism and Indeterminate Identity. Journal of Philosophical Research 40: 205-25

Parsons, T. (1980), Nonexistent Objects, New Haven: Yale University Press.

Parsons, T. (2000), Indeterminate Identity: Metaphysics and Semantics, Oxford: Oxford University Press

Parsons, T. (2011), Fictional Characters and Indeterminate Identity, in F. Lihoreau (ed), Truth in Fiction, Berlin: de Guyter, pp. 27-42

Parsons, T. and Woodruff, P. (1995), Worldly Indeterminacy of Identity. Proceedings of the Aristotelian Society 95: 171-91

Pelletier, F. J. (1989), Another Argument against Vague Objects. The Journal of Philosophy 86(9): 481-92

Pinillos, A. (2003), Counting and Indeterminate Identity. Mind 112(445): 35-50

Rapaport, W. J. (1978), Meinongin Theories and a Russellian Paradox. Nô̂s 12: 153-180

Routley, R. (1980), Exploring Meinong's Jungle and Beyond, Canberra: Australian National University

Russell, B. (1923), Vagueness. Australasian Journal of Philosophy and Psychology 1: 84-92

Sainsbury, R. M. (2010), Fiction and Fictionalism, London: Routledge

Salmon, N. (1981), Reference and Essence, Princeton: Princeton University Press

Salmon, N. (1998), Nonexistence. Nô̂s 32: 277-319

Schiffer, S. (1996), Language-Created Language-Independent Entities. Philosophical Topics 24: $149-66$

Schnieder, B. e von Solodkov, T. (2009), In Defense of Fictional Realism. The Philosophical 
Quarterly (59.234): 138-49

Searle, J. (1975), The Logical Status of Fictional Discourse. New Literary History 6(2): 31932

Sider, T. (2001), Four Dimensionalism: An Ontology of Persistence and Time, Oxford: Oxford University Press

Sider, T. (2003), Against Vague Existence. Philosophical Studies 114: 135-46

Sider, T. (2009), Against Vague and Unnatural Existence: Reply to Liebesman and Eklund. Noûs 43: 557-67

Smith, N. J. J. (2008), Why Sense cannot be made of Vague Identity. Nô̂s 42: 1-16

Soames, S. (2003), Higher-order Vagueness for Partially Defined Predicates, in C. J. Beall (ed), Liars and Heaps, Oxford: Clarendon Press, pp. 128-50

Sorensen, R. (1988), Blindspots, Oxford: Oxford University Press

Taylor, D. E. and Burgess, A. (2015), What in the World is Semantic Indeterminacy? Analytic Philosophy 56: 298-317

Thomasson, A. L. (1999), Fiction and Metaphysics, Cambridge: Cambridge University Press

Thomasson, A. L. (2003), Speaking of Fictional Characters. dialectica 57: 205-23

Thomasson, A. L. (2010), Fiction, existence and indeterminacy, in John Woods (ed.) Fictions and Models: New Essays, Munich: Philosophia Verlag, pp. 109-48

van Inwagen, P. (1977), Creatures of Fiction. American Philosophical Quarterly 14: 299-308 van Inwagen, P. (1988), How to reason about Vague Objects. Philosophical Topics 16: 255-84 van Inwagen, P. (1990), Material Beings, Ithaca: Cornell University Press

van Inwagen, P. (2009), Indeterminacy and Vagueness: Logic and Metaphysics. European Journal for Philosophy of Religion 1.2: 1-19

Voltolini, A. (2006), How Ficta Follow Fiction. A Syncretistic Account of Fictional Entities, Dordrecht: Springer 
Voltolini, A. (2010), Against against Fictional Realism. Grazer Philosophische Studien (80): $47-63$

Walton, K. L. (1990), Mimesis as Make-Believe: On the Foundations of the Representational Arts, Cambridge Mass: Harvard University Press

Williams, J. R. G. (2008), Multiple actualities and ontically vague identity. Philosophical Quarterly 58: 134-54

Williamson, T. (1994), Vagueness, London: Routledge

Williamson, T. (2002), Vagueness, Identity and Leibniz's Law, in A. Bottani, M. Carrara and P. Giaretta (eds), Individual Essence and Identity, Dordrecht: Kluwer, pp. 273-304

Woodward, R. (2017), Identity in Fiction. Philosophy and Phenomenological Research 94.3: $646-71$

Zalta, E. N. (1983), Abstract Objects: An Introduction to Axiomatic Metaphysics, Dordrecht: Reidel

Zalta, E. N. (2000), The Road Between Pretence Theory and Abstract Object Theory, in A. Everett and T. Hofweber (eds), Empty Names, Fiction, and the Puzzles of NonExistence, Stanford: CSLI Publications, pp. 117-147

Zardini, E. (2014), Evans Tolerated, in K. Akiba and A. Abasnezhad (eds), Vague Objects and Vague Identity, Dordrecht: Springer, pp. 327-52 